\title{
Multi-Level Effects Driving Cognitive and Behavioral Variability among Prairie Voles: Insights into Reproductive Decision-Making from Biological Levels of Organization
}

\author{
Santiago A. Forero Alexander G. Ophir \\ Department of Psychology, Cornell University, Ithaca, NY, USA
}

\section{Keywords \\ Alternative mating tactics - Animal cognition - Proximate and ultimate mechanisms - Social behavior - Social brain}

on the level of the organism to discuss how cognitive processes emerge as traits, and how they can be studied as important mechanisms driving the expression of behavior.

(c) 2022 The Author(s).

Published by S. Karger AG, Basel

\begin{abstract}
Behavioral phenotypes play an active role in maximizing fitness and shaping the evolutionary trajectory of species by offsetting the ecological and social environmental factors individuals experience. How these phenotypes evolve and how they are expressed is still a major question in ethology today. In recent years, an increased focus on the mechanisms that regulate the interactions between an individual and its environment has offered novel insights into the expression of alternative phenotypes. In this review, we explore the proximate mechanisms driving the expression of alternative reproductive phenotypes in the male prairie vole (Microtus ochrogaster) as one example of how the interaction of an individual's social context and internal milieu has the potential to alter behavior, cognition, and reproductive decision-making. Ultimately, integrating the physiological and psychological mechanisms of behavior advances understanding into how variation in behavior arises. We take a "levels of biological organization" approach, with prime focus placed
\end{abstract}

Karger@karger.com www.karger.com/bbe

Karger"

BOPEN ACCESS
(C) 2022 The Author(s)

Published by S. Karger AG, Basel

This is an Open Access article licensed under the Creative Commons Attribution-NonCommercial-4.0 International License (CC BY-NC) (http://www.karger.com/Services/OpenAccessLicense), applicable to the online version of the article only. Usage and distribution for commercial purposes requires written permission.
Biological life and the mechanisms that drive it are inherently organized into a hierarchical structure [MacMahon et al., 1978]. These levels of organization span the smallest units of matter (i.e., atoms, or even sub-atomic particles), through simple levels or organization like molecules, cells, individuals, and so on, to the highest level of organization involving all living things (e.g., the biosphere) [Maynard-Smith and Szathmary, 1997; Adami et al., 2000]. Such levels of organization provide a framework that enables scientists to conceptualize the natural order within life. Although a focus at each level has inherent value, perhaps no other level of biological organization is more important to the study of behavior than that of the individual. As a phenotypic trait at the individual level, behavior is controlled by higher and lower levels of biological organization to some degree (e.g., at the population level and at the level of the tissue, the cellular, or

Correspondence to:

Alexander G. Ophir, ophir@ cornell.edu 
even sub-cellular levels). This interaction can be seen in the way behavior is impacted by the population and community it experiences in its immediate environment, and the way gene products and signaling molecules shape behavior. Thus, to provide a complete picture of behavior at the individual level, one must also account for factors that extend beyond the individual level of analysis.

The framework provided by the inherent hierarchical nature of levels of biological organization can lead to new ways of thinking about behavior at the individual level. Indeed, approaching the study of behavior from this perspective allows one to view complex behavior as an emergent property that arises from the interactions of adjacent (higher and lower) level traits [Craver and Bechtel, 2007; Eronen and Brooks, 2018]. For example, although one can examine an individual (and its behavior) in its own right, individuals are comprised of cellular and molecular level traits, each of which act within and across their own unique levels of biological organization. Therefore, although mechanisms and traits at each level are often studied independently, there is much to be gained by studying them in concert [for an example see O'Connell and Hofmann, 2012a].

This framework also provides a unique perspective on cognition, which can be thought about as an emergent property resulting from the interactions of multi-level traits and proximally functions to process environmental information and coordinate decision-making at the level of the individual. When studying the expression of behavior, it is critical to consider the multi-level traits that contribute to the cognitive processes influencing behavior. Cellular level traits (like the extent of neural connectivity) and molecular level traits that regulate cellular function (such as concentrations of signaling molecules, densities of receptors, and differential gene regulation) are examples of the sub-individual level traits that are highly variable and that profoundly impact the cognitive processes observable at the individual level.

Integrating across multiple levels of analysis can be informative about the broader suite of mechanisms controlling phenotypic expression [O'Connell and Hofmann, 2012a]. Below, we will discuss points of interaction across levels of biological analysis that provide a foundation upon which to better understand reproductive decision-making. To explore the kinds of interactions between and within levels of biological organization that can shape the individual and its behavior, we will assess the multi-level traits impacting the cognitive processes driving reproductive decision-making in the socially monogamous prairie vole (Microtus ochrogaster). Specifical- ly, we focus on the alternative reproductive tactics for which prairie voles have become known because these behavioral decisions represent the culmination of assessing the internal and external environments (i.e., super-individual and supra-individual levels of biological organization) to make the most optimal choices an individual can, based on the information available to them. To avoid confusion between using the same term to formally refer to levels of organization and to their more colloquial uses, we will italicize terms when referring to a particular level of organization (i.e., "individual" level of organization or "individual" animal).

Although a good argument can be made that all levels of biological organization have the potential to affect each other, we focus our discussion on the levels of organization with the most immediate potential to directly impact the individual level: the population, cellular, and molecular levels (see below). Indeed, individual behavior plays an active role in shaping the evolutionary process by responding to factors from the external environment [Bateson, 2004; Odling-Smee et al., 2013], and integrating the physiological and psychological mechanisms of behavior provides clear explanations about the origins of individual variation in behavior [Duckworth, 2009]. In particular, we view the many internal processes of cognition as mechanisms of behavior that operate at the individual level and that primarily emerge from the interactions of the levels of biological organization immediately below and above the individual level. Therefore, we first briefly discuss the relationship between cognition and behavior. We follow this with a discussion of the suite of behaviors that distinguish alternative mating tactics among prairie voles and focus on the cognitive processes driving these behaviors. We then explore how multi-level traits (above - at the population level, and below - at the cellular and molecular levels) interact at the level of the individual to shape cognitive processes modulating decision-making. To conclude, we argue that taking a multi-level approach to understanding cognition and behavior provides new insights into and explanations how phenotypic variation arises.

\section{Cognitive Processes as Mechanisms of Behavior}

Cognitive processes, such as learning, memory storage, and information integration, can all be considered mechanisms of behavior because of their ability to modulate decision-making [Mendelson et al., 2016]. Through these coordinated processes, individuals express different forms of cognition (e.g., individual recognition, spatial 
navigation) that help them acquire environmental information, store it, and use it to optimize decision-making [Dukas, 1998; Shettleworth, 2010; Mendelson et al., 2016]. By coordinating patterns of interaction with environmental factors, cognition can culminate to form adaptive fitness-enhancing behaviors across contexts [Griffin et al., 2015]. Support for how cognition coordinates adaptive behavior comes from a relationship recently found between variation in personality and variation in learning across taxa [Dougherty and Guillette, 2018]. Notably, there exists a positive relationship between cognition and "boldness" in response to predation, such that bolder animals are quicker to learn new associations and show more correct responses compared to "shy" individuals [Dougherty and Guillette, 2018]. These data provide just one example of support for the idea that cognitive mechanisms can be effectively studied by assessing their effects on shaping behavior [Niv, 2021]. Furthermore, we can begin to integrate across more levels of biological organization by gaining a deeper understanding of the underlying neural, hormonal, and genetic activity driving the expression of these cognitive mechanisms.

The extent of neural investment in brain areas (i.e., volume) to support spatial memory among nonhuman animals provides perhaps the most classic example of the neural roots of cognition [Sherry et al., 1989, 1992; Jacobs et al., 1990; Hampton et al., 1995]. Many species of foodstoring birds rely on the ability to remember the spatial location of objects for food retrieval. For example, black capped chickadees demonstrate hippocampal volumetric plasticity, which directly relates to their spatial cognitive abilities [Hampton et al., 1995; Krebs et al., 1996]. At the molecular level, specific neurotransmitter receptor density differences have also been shown to correlate with behavioral variation within monogamous (prairie voles) and nonmonogamous (meadow voles) vole species [Ross et al., 2009]. Interestingly, although the absolute size of the hippocampus (HPC) shows astounding ability to predict spatial learning and memory [Sherry et al., 1989, 1992], in some cases subtler differences at the sub-cellular level can also account for such cognitive differences. For instance, male prairie voles demonstrate better performance in the hippocampally dependent Morris water task than females, but hippocampal volume and cell density are similar between the sexes [Rice et al., 2017]. Notably, the neuromodulator oxytocin (OT) is known to impact learning and memory [McEwen, 2004; Ophir, 2017], and a significant sex difference in hippocampal OT receptor (OTR) density explains the behavioral difference [Rice et al., 2017].

Cognitive and Behavioral Variability in

Reproductive Decision-Making
Population level traits (population size, density, and demographics) can produce environmental pressures that also affect individual behavior [Gil et al., 2018] by altering the selective forces resulting from social factors within a given population. For example, alternative mating tactics within a population can be under density-dependent selection, where the expression and success of one tactic depends on the frequency at which other individuals in the population express a given tactic [Kokko and Rankin, 2006; Rice et al., 2018; Bouffet-Halle et al., 2021]. Thus, the proximate mechanisms of population dynamics can have consequences on the reproductive success of the individual and the ultimate evolutionary trajectory of the species.

\section{Alternative Mating Tactics in the Male Prairie Vole}

Sexual selection commonly creates intrasexual alternative mating phenotypes, often observable in body size, shape, and/or coloration [Dominey, 1984; Angeloni et al., 2002; Oliveira et al., 2008; Shuster and Wade, 2019]. For example, male jumping spiders (Maevia inclemens) can develop one of two morphs (tufted morph and striped morph), each with distinct patterns of coloration and associated morph-typical courtship behavior. Whereas "tufted" males court from afar with honest signals, "striped" males court closer to females while reducing female aggression in this cannibalistic species by mimicking aposematic prey [Lietzenmayer et al., 2019]. In many other contexts, sexual selection can impact behavioral phenotype while leaving the outward appearance relatively unchanged [Baur et al., 2019]. Prairie voles provide a good example of this form of alternative reproductive tactics. Indeed, there is little apparent physical difference found between animals adopting each tactic [Ophir et al., 2008b; McGuire and Getz, 2010; but see Madrid et al., 2020]. In this species, males adopt one of three behaviorally distinguishable alternative mating tactics ("true residents," "roving residents," and "wanderers" [Madrid et al., 2020]). Residents are the more common mating tactic [Getz et al., 1987, 1993; Solomon and Jacquot, 2002; Ophir et al., 2008b] characterized as males that form pair bonds, establish a territory that overlaps primarily just one female, and appear to mate-guard their partner from other males. However, resident males can be further subdivided into two subtypes. Whereas "true residents" appear to invest heavily in mate guarding and forgo engaging in extra-pair mating, "roving residents" are bonded but seek extra-pair copulations (EPCs) at the cost of effort

Brain Behav Evol 2022;97:225-240 227 
dedicated to mate-guarding. In contrast to either form of resident, "wanderers" do not form pair bonds, have expansive (un-defendable) home ranges, intrude frequently into the home ranges of other conspecifics, and appear to mate opportunistically when possible. Notably, prairie vole mating tactics are reversible, with divorce and repairing commonly observed [McGuire and Getz, 2010; Kenkel et al., 2019; Shuster et al., 2019; Harbert et al., 2020].

Evidence supports the hypothesis that the resident tactic might be associated with greater reproductive success [Ophir et al., 2008b; McGuire and Getz, 2010; but see Shuster et al., 2019] and, therefore, might be the preferred tactic among males. Indeed, when sexually naïve single males are presented with two sexually receptive unfamiliar females in the lab, they will preferentially bond with one female, while ignoring or becoming increasingly aggressive with the other [Blocker and Ophir, 2016]. This has led to prairie voles being considered a socially monogamous species. Indeed, between $60 \%$ and $75 \%$ of males adopt residency [Madrid et al., 2020]. However, field studies report that a significant proportion of males adopt a wandering tactic ranging between $32 \%$ and $46 \%$ in high-population and low-population density months, respectively [Getz et al., 1987, 1993].

As mentioned above, not many dimorphic physical differences have been found between prairie vole sexes, or between alternative mating tactics within sexes. One such difference shows that, compared to residents, wanderers appear to have shorter anogenital distances (AGD; a marker of a less masculinized phenotype), and (shorter) AGDs correlate with (lower) sperm count [Ophir and Delbarco-Trillo, 2007]. Females also prefer males with longer AGDs in the lab [Ophir and Delbarco-Trillo, 2007], supporting the hypothesis that a resident tactic may be the most reproductively beneficial tactic for males.

Relatively little is directly known about what role aggression has in defining natural prairie vole mating tactics. In the lab, sexually naïve male prairie voles typically display low levels of aggression, with instances of aggressive behavior increasing as males mature [Kelly et al., 2018] and notably after undergoing the life history transition of becoming pair bonded shortly after mating [Winslow et al., 1993]. However, studies have not measured how innate aggressiveness in males relates to their choice to adopt a certain mating tactic, presumably because of the inability to measure alternative mating tactics in the lab or difficulty to perform direct tests of aggression in the field. Notably, it has been shown that circulating testosterone concentrations do not mediate aggressive behav- iors in adult male prairie voles [Demas et al., 1999], suggesting that there may not be large innate intra-individual differences in aggression. On the other hand, AGDs are morphological markers of developmental exposure to sex steroids and often relate to the most competitive phenotypes [vom Saal et al., 1983; Clark and Galef, 1998; Drickamer, 1996]. As just mentioned, resident male prairie voles have longer (more masculinized) AGDs than wanderers, and females in the lab prefer males with longer AGDs, indicating that they are more likely to bond because females more readily accept their courting advances [Ophir and Delbarco-Trillo, 2007]. The relationship between AGD, circulating sex steroids, and aggression has not been explored in prairie voles; however, in other rodents AGD is often indicative of aggression and dominance [vom Saal et al., 1983; Drickamer, 1996], suggesting a correlation among residents and dominant/aggressive territorial behaviors. Whether such a possible correlation is predictive or reflective of residency behavior, however, remains an open question.

Our discussion has focused on male reproductive tactics so far; however, female tactics and how they interact with male tactics are profoundly understudied and merit serious consideration. Importantly, female prairie voles also appear to display alternative mating tactics [Zheng et al., 2013b; Madrid et al., 2020]. We have shown that females living in a semi-natural field enclosure have similar proportions of residents and wanderers, but a slightly larger proportion of females wandered compared to males in our experiments [Ophir et al., 2008a; Zheng et al., 2013b]. We note that we are unsure if the labels of "resident" and "wanderer" are equivalent in the two sexes, and caution should be taken when generalizing terms in discussions of male and female reproductive decisionmaking. For example, a low percentage of single (wandering) females may result from a divorce or from the death of the partner [McGuire and Getz, 2010] rather than the choice to forgo pair bonding. However, field studies suggest that previously paired females that become single may remain reproductively active by mating with wandering males. Indeed, these females have high visitation rates from wanderer males and typically give birth to their offspring [McGuire and Getz, 2010]. Interestingly, "widow" females form novel bonds at a low rate in the wild (19\%) and in the lab (14\%) [Getz et al., 1993; Pizzuto and Getz, 1998], suggesting that a low re-bonding rate by "widow" females may contribute to a male's decision to forgo pair bonding [Forero et al., unpubl. data]. Current work in our lab is focused on uncovering how and why widow females forgo re-bonding, and how this choice im- 
pacts male reproductive decision-making. Rice et al. [2018] modeled the effects that females have on the decisions that males make and provided theoretical support for the hypothesis that more available females increase the probability that roving will have greater reproductive payoffs over remaining a true resident. Taken together, many important questions remain about what influences female reproductive decision-making, not necessarily in terms of who they select as mates (an area that is very well studied in general), but more in terms of how they choose to mate and with what frequency. Even less is known about the neural mechanisms that modulate such decision-making among females, leaving a significant gap in our understanding of this system and the mechanisms guiding female reproductive decision-making [but see Zheng et al., 2013b]. Because of the current imbalance in available data on female reproductive tactics in prairie voles, we focus the remainder of this review primarily on males, but we highlight a need to shine more light on the other half of this particularly interesting system.

\section{Cognitive Variation between and within Mating Tactics}

Understanding forms of cognition that underly natural behavioral variation provides an opportunity to elucidate the mechanisms that shape reproductive decisionmaking. As just discussed, prairie voles demonstrate a spectrum of variation in both pair bonding and mate fidelity, and they can, therefore, serve as a system ripe for exploring reproductive decision-making. To truly understand the evolution and expression of alternative mating tactics, one must outline the cognitive mechanisms and specific environmental contexts for which behavior will optimize reproductive success. Here, we assume that the reproductive decision-making process associated with each tactic should ultimately promote individual reproductive success for those given tactics. Notably, social cognition, spatial cognition, and the integration of sociospatial information appear to contribute to the general character of prairie vole mating tactics. Indeed, it has been suggested that socio-spatial cognition (e.g., spatial learning and memory, individual recognition and discrimination, and the ability to associate identity within a spatial context) could be a critical factor in determining the alternative mating tactic most likely to maximize individual reproductive success [Phelps and Ophir, 2009; Prounis et al., 2015; Ophir, 2017]. Cognitive variation may provide a mechanistic account for the observable variation in behavior that distinguishes between prairie vole mating tactics. In the following sections, we discuss the cognitive profiles that may be associated with optimizing behavior within each prairie vole mating tactic.

\section{Residents}

Resident males are characterized as being territorial, demonstrating high rates of aggression towards unfamiliar conspecifics, and expressing social and sexual preferences for one female [Williams et al., 1992; Gobrogge et al., 2007]. To succeed in these endeavors, resident males presumably rely on acute socio-spatial learning and memory abilities. Specifically, social recognition (knowing who your neighbors are) and socio-spatial memory (knowing where your neighbors are) should help optimize territorial behavior among resident males [Ophir, 2017]. In fact, we have shown that social recognition for familiar conspecifics among single males varies across social context [Zheng et al., 2013a], and paired males are better than single males at social recognition when strangers are presented in novel spatial contexts [Forero et al., unpubl. data]. This ability to integrate social and spatial information presumably influences a male's decision to form and maintain a pair bond, mate-guard, and defend (relatively small) territories [Phelps and Ophir, 2009]. Territorial behavior and mate-guarding in prairie voles likely also helps deter cuckoldry and ensure fitness and paternity certainty [Wolff and Dunlap, 2002; Phelps and Ophir, 2009]. Indeed, males who only sire offspring with their partner have been shown to have smaller home ranges than males who sire offspring with extra-pair females [Okhovat et al., 2015]. Although we are unaware of any studies demonstrating that agonistic interactions are modulated as a function of social recognition (i.e., the dear enemy effect [Fisher, 1954]), it would be interesting to determine if social recognition of familiar competitor neighbors and other unfamiliar competitors modulates male aggression in a natural territorial context, particularly among residents. In this sense, the acquisition, storage, and integration of social and spatial information may be particularly important for pair-bonded males to make decisions that maximize their reproductive success.

\section{Roving and True Residents}

Although lab data suggest that sexually naïve males prefer to bond [Blocker and Ophir, 2016], a considerable number of pair-bonded males living in semi-naturalistic field contexts over longer periods of time reproduce with extra-pair females [Ophir et al., 2008a]. As mentioned above, a distinction can be made between resident males 
that pursue EPCs (roving residents) and those that do not (true residents). Notably, space use within the constraints of generalized "resident behavior" appears to correlate with the natural variation in spatial cognition expressed by resident males [Rice et al., in review] and could explain the differences between true residents and roving residents. Furthermore, compared to true resident males that exclusively sire offspring with their partner, males that mate with nonpartners have larger territories/home ranges, higher rates of same-sex encounters in those home ranges, and are more likely to intrude on a resident's territory [Ophir et al., 2008b; Okhovat et al., 2015; Rice et al., in review]. Interestingly, the frequency with which resident males that produced offspring with extra-pair mates (i.e., roving residents) intrude into another conspecific's territory is correlated with the rate at which they are intruded upon [Okhovat et al., 2015]. Therefore, successful rovers must maximize the benefits of gaining EPCs with the costs of cuckoldry [Phelps and Ophir, 2009]. Like true residents, rovers are believed to rely on remembering where their mate is and monitoring the activity of their neighbors. However, unlike true residents, rovers are thought to be less socially selective of conspecifics, potentially creating the opportunity for extra-pair mating. More empirical research is necessary to confirm this prediction and to understand the cognitive mechanisms enabling rovers to monitor their neighbor's activity and assess the risks of seeking EPCs.

\section{Wanderers}

Although most male prairie voles in a given population appear to prefer to form pair bonds, about one-third or more of males in a population express a nonbonded wanderer tactic [Getz et al., 1993; Ophir et al., 2008a]. Wanderer males do not express pair bonds and do not mate-guard; instead, they appear to maximize reproductive success by promiscuously mating with reproductively available females (both single females and bonded but promiscuous females) [Ophir et al., 2008a; McGuire and Getz, 2010]. Wanderers have larger home ranges compared to residents [Ophir et al., 2008a; Phelps and Ophir, 2009]. Furthermore, wanderers commonly overlap the home ranges of other conspecifics and do not express social or spatial fidelity with any particular female [Getz et al., 1993; Solomon and Jacquot, 2002; Ophir et al., 2008a]. There is a long-held assumption that bigger home ranges require better navigational ability [Gaulin and FitzGerald, 1988; Sherry et al., 1992; Roth and Pravosudov, 2009]. However, in the case of wanderers, the opposite might be true, and they might live up to their name in which they (somewhat aimlessly) wander throughout their local environment.

Wanderer males in the field appear to be comparable to virgin single males in the lab, and lab studies on social cognition might, therefore, generalize to the wandering phenotype. In particular, single males do not socially discriminate between novel or familiar females in the lab [Zheng et al., 2013a], presumably interfering with their ability to form selective affiliations or reflecting an apathy for one female over the other. In contrast, bonded males readily integrate novel social information and discriminate between individuals [Blocker and Ophir, 2015]. Moreover, bonded males appear to do this regardless of spatial context, whereas nonbonded males take longer to integrate novel social and spatial information [Forero et al., unpubl. data]. This kind of poor socio-spatial memory has been characterized as "adaptive forgetting" for wandering males [Phelps and Ophir, 2009; Ophir, 2017]. This hypothesis argues that weak associations between a location and negative social experiences can benefit wanderers by increasing their opportunities to engage in cuckoldry by returning to sites where they might have previously experienced deterrents (e.g., scent marks of territorial residents) or punishing (i.e., antagonistic) encounters with resident males. However, more research is necessary to more clearly define the social cognition expressed by wandering males.

\section{Multi-Level Effects Shaping Prairie Vole Cognition}

Variability in the mating tactics observed in male prairie voles appears to be rooted, at least in part, in differences in social and spatial cognition. In other words, the behavioral differences that are readily observable between residents (true and roving) and wanderers are characterized by the patterns of space use they demonstrate and the ability to discriminate between and among conspecifics. Thus, these cognitive differences observed within and between mating tactics provide an opportunity to study the multi-level mechanisms shaping the expression of variable behavior. Moreover, prairie vole mating tactics are plastic, and flexibility within these cognitive mechanisms may have evolved to enable individuals to adapt to their local context. Differences in the social environment and the internal milieu of an individual are very likely to dictate the conditions of those local contexts, thereby altering the cost-benefit assessments involved in the cognitive processing central to reproductive decision-making. 


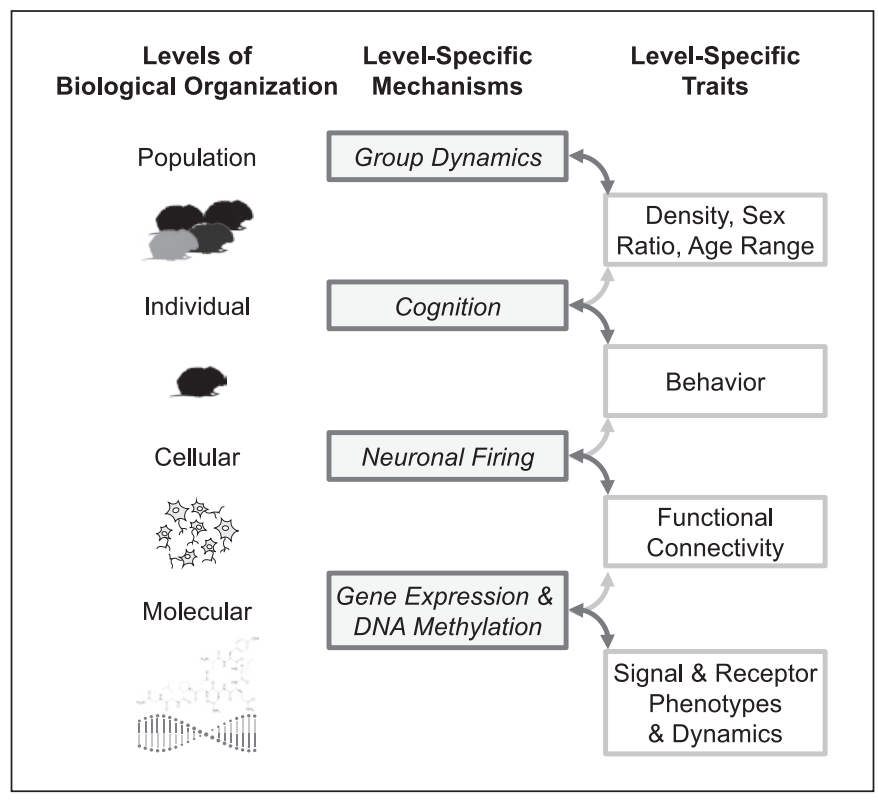

Fig. 1. Levels of biological organization spanning the population to the molecular levels. Center and right columns provide examples of level-specific mechanisms and corresponding traits discussed in the article that operate at each level. These mechanisms and traits both influence and are influenced by each other at adjacent levels. Darker grey lines represent descending influences; lighter grey lines represent ascending influences.

Although it is convenient to focus on a single level of biological organization, the different levels are inherently integrated and reciprocally affect each other (Fig. 1). For example, the population level represents a major environmental factor in which individuals live and can reciprocally affect and be affected by the behavior of other individuals from the population. Similarly, the underlying mechanisms captured by levels of organization below the individual, such as neural function, can have bottom-up effects on behavior, while actions and experiences at the individual level can also have top-down feedback effects, shaping neural, hormonal, and genomic dynamics. To better understand how behavioral variability arises within and between tactics, we next explore how population level factors, individual level factors, and underlying cellular and molecular level factors shape the cognitive processes that influence reproductive decision-making.

\section{Population Level Effects}

Differences in cognition and behavior are clearly influenced by the social landscape individuals experience throughout development and in adulthood. Therefore, we must consider the emergent social environment and the impact that population level traits (such as population density and sex ratio) can have on the individual. In general, population demographic heterogeneity can influence male reproductive decision-making by altering the social factors to which individuals must respond. Natural prairie vole populations experience large fluctuations in population density, potentially in response to predation [Getz et al., 1987]. For example, low population densities are often seen in the spring-summer months and high population densities are more common in the autumnwinter months [Getz et al., 1993]. These population dynamics can affect individual cognition by altering resource availability [e.g., food, mates; Ryan et al., 2009; Spencer et al., 2017], thereby altering the kinds of behaviors individuals must express to successfully acquire those resources. Similarly, differences in population densities set different probabilities for social interaction; denser populations have greater probabilities of social interactions with more conspecifics. Notably, Sabol et al. [2020] found that the number of social connections male and female prairie voles had (i.e., their sociability) demonstrated an inverse- $U$ relationship with the number of mates and their reproductive success. Thus, population density and population dynamics have a clear ability to not only impact the evolution of that population, but they can shape the reproductive payoffs associated with different patterns of behavior within the population.

Could different social contexts resulting from different population level conditions affect mating tactics differentially? Despite the association between moderate population density and greater reproductive success [Sabol et al., 2020], residents appear to have greater reproductive success [Ophir et al., 2008a; Solomon and Keane, 2018], indicating that residents might benefit from living in intermediate population densities. Alternatively, high population densities could create more potential mating opportunities and may increase the reproductive payoffs associated with mating outside the pair bond. In these cases, a roving resident or wanderer phenotype might be advantageous. Indeed, field studies show that higher population densities increase the overlap of a paired male's territory with other females [Streatfeild et al., 2011; Blondel et al., 2016] and monogamy is more prevalent during periods of low population density [Carter et al., 1986]. Increased home range overlaps are characteristic of wanderers, but not residents [Ophir et al., 2008a]. Additionally, a computational model assessing the fitness payoffs of roving within a population shows that the decision to become a rover may be strongly dependent on the proportion of rovers (and wanderers) in the social envi- 
ronment [Rice et al., 2018]. This study demonstrated that the fitness payoff of expressing a rover phenotype may be under positive frequency-dependent selection, where benefits increase as the number of rovers in the population increases. This shift in the potential reproductive payoff for different resident tactics is presumably attributable to the associated increase in unguarded females left by the increased roving activity [Rice et al., 2018]. Thus, like residency, the evolution or maintenance of roving and wandering is dependent on mechanisms associated with population cycles and densities and how those mechanisms alter the behavior of the individual.

A population's sex ratio can also influence individual level traits. Live trapping data indicate that natural prairie vole population sex ratios are on average about 1:1, but they do fluctuate $+/-10 \%$ throughout the year because of predation, migration, and resource abundance [Myers and Krebs, 1971]. Moreover, these reported sex ratios did not account for the proportion of reproductively available and unavailable individuals (i.e., the operational sex ratio). Nevertheless, this natural variability in sex ratio potentially creates opportunities for individuals to behave differently under different contexts. Indeed, recent data suggest that males living in a population with a malebiased sex ratio display better spatial memory than males living in a female-biased context [Rice et al., 2019]. This outcome is presumably a result of increased mate competition and the need for males to remember where available females and male competitors are in space [Rice et al., 2019]. Therefore, the impacts of sex ratio on population dynamics also appear to affect individual cognition, which in turn could impact reproductive decision-making. Taken together, these studies support the hypothesis that higher-level traits can shape lower-level traits and highlight the need to conduct more research aimed at understanding how individuals process population level effects and the down-stream consequences of this on individual behavior.

\section{Individual Level Effects}

One way in which individuals can gain information about population dynamics is through information gathering about other individuals. In this way, exposure to social partners and their phenotypes has the potential to influence individual cognition and behavior. Indeed, cues associated with female prairie vole fertility and sexual receptivity appear to inform male prairie voles about the potential payoffs of forming a pair bond at that moment with a given potential partner. For instance, males appear to be sensitive to female chemical sexual signals, investi- gating the dirty bedding of receptive females more than bedding from other males or clean bedding [ValeraMarín et al., 2021]. Lesions of the vomeronasal organ, an organ important for processing sexual cues in rodents, greatly reduces reproductive performance in males, with only $22 \%$ of lesioned males siring offspring compared to $75 \%$ of intact males [Wekesa and Lepri, 1994].

In nature, males presumably often encounter both fertile and sexually unreceptive females. Yet, it is unclear to what extent these overt cues of detectable female sexual receptivity influence male reproductive decision-making. Notably, female prairie voles are induced ovulators and, therefore, require prolonged exposure (24-48 h) to male pheromonal stimuli to induce ovarian activity [Carter et al., 1980; Wysocki et al., 1991] and behavioral receptivity [Carter et al., 1988]. Indeed, vomeronasal organ lesions prevent estrus induction in females [Wysocki et al., 1991]. Inhibiting estrus activity in females via ovariectomy disrupts normal mating and bonding behaviors and hormone replacement rescues these behaviors [Dluzen and Carter, 1979; Carter et al., 1988; Hnatczuk and Morrell, 1995]. Similarly, males fail to display partner preferences when paired with an ovariectomized female that cannot become pregnant or when there is a delay (approximately $48 \mathrm{~h}$ ) in mating after pairing [Curtis, 2010]. Thus, a male's ability to detect female sexual receptivity and the necessary reproductive investment in their partner, while also assessing their own potential for reproductive success, will interact to presumably shape both the reproductive decisions that they make to maximize individual reproductive success within the context of the particular mating tactic they adopt.

A female's bonding history may also impact a male's decision to bond. Males have been shown to readily rebond with novel females [Kenkel et al., 2019; Harbert et al., 2020]. However, when a male is co-housed and allowed to mate with a "widowed" female [Thomas and Wolff, 2004; i.e., a previously bonded female that has been separated from her partner], he fails to express a partner preference [Forero et al., unpubl. data]. These data support previous evidence that found that male prairie voles prefer to spend time and mate with unmated females compared to females that have previously mated [Ferguson et al., 1986]. Additionally, lab and field data show that widow females rarely re-bond (approximately only 20\%), regardless of male availability [Getz et al., 1993; Pizzuto and Getz, 1998]. More research is necessary to determine if this is a result of a male's decision to forgo bonding or a lack of bond reciprocation by the female, but there is some support indicating that a male's failure to bond with 


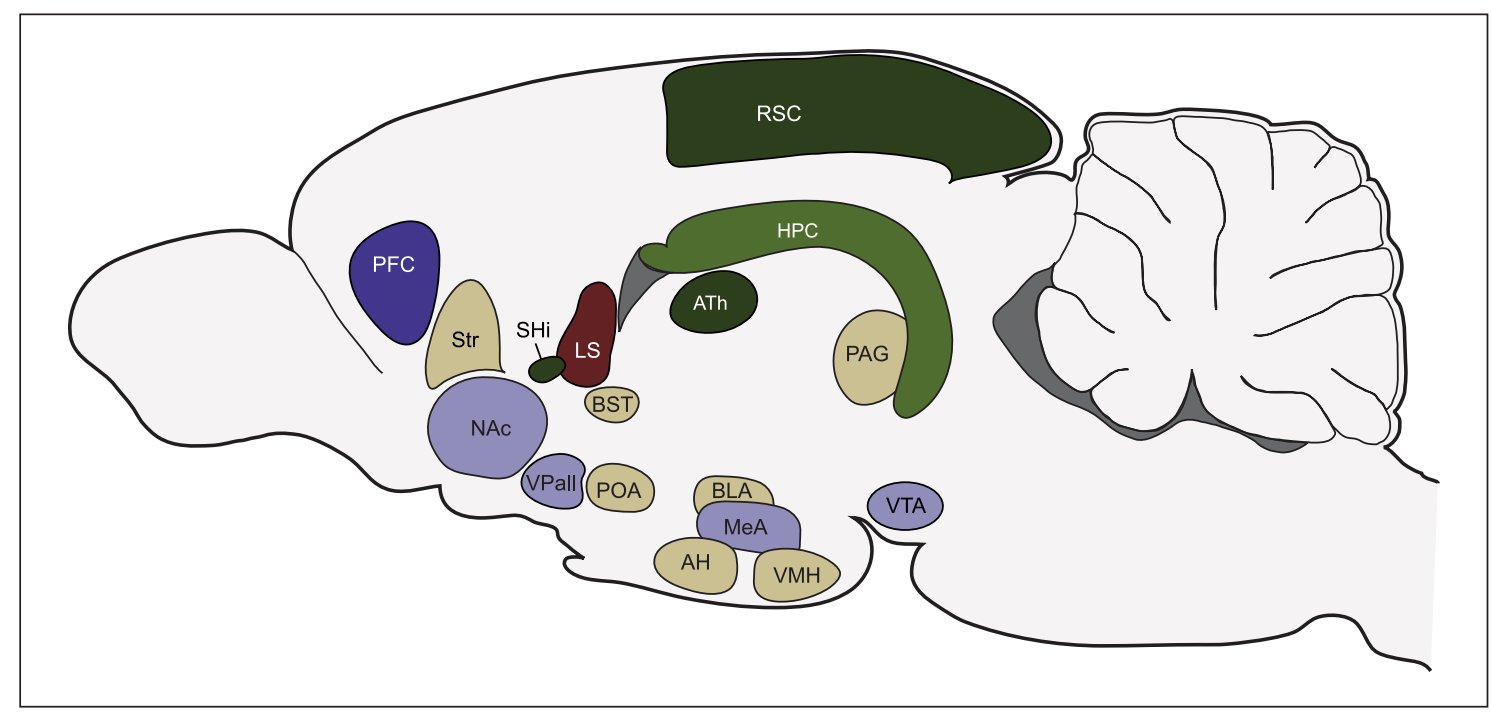

Fig. 2. Schematic of brain structures central to the prairie vole pair bonding neural circuit, the SDMN, and the SSMC circuit. The prairie vole PBNC is drawn in blue. Dark blue represents areas exclusively part of the PBNC; light blue represents areas that are part of both the PBNC and the SDMN. The SSMC is drawn in green. Dark green represents areas exclusively part of the SSMC; light green represents areas that are part of both the SSMC and the SDMN. Beige areas represent nuclei that are exclusively part of the SDMN. One area, the LS (red), is considered part of all three networks. AH, anterior hypothalamus; ATh, anterior thalamus; BLA,

females is partly driven by females' decisions to forgo bonding due to the effects of losing a partner [Thomas and Wolff, 2004]. A large proportion of reproductive single females resulting from "divorce" or "widowing" in the population may facilitate the reproductive success of wanderer males. In fact, even though wanderer reproductive success is poor compared to residents [Ophir et al., 2008a], wanderers produce more offspring when reproductive single females are more common in the population [McGuire and Getz, 2010]. Thus, the individual lifehistory contexts of females have the power to alter the probability of individual males adopting and/or succeeding within a particular chosen tactic by shaping the social environmental (population) factors these males will encounter.

Developmental histories of individuals also have the potential to alter cognitive and behavioral phenotypes [Schuppli et al., 2016]. Prairie voles display a complex system of offspring care, including sole maternal care, biparental care, and occasionally additional alloparental care from philopatric nonreproductive offspring [Thomas and Birney, 1979; Getz et al., 1993]. Thomas and Birney [1979] demonstrated that fathers engage in all aspects of basolateral amygdala; BST, bed nucleus of the stria terminalis; HPC, hippocampus; LS, lateral septum; MeA, medial amygdala; NAc, nucleus accumbens; PAG, periaqueductal grey; PBNC, pair bonding neural circuit; PFC, prefrontal cortex; POA, preoptic area of the hypothalamus; RSC, retrosplenial cortex; SDMN, social decision-making network; SHi, septohippocampal nucleus; SSMC, socio-spatial memory neural circuit; Str, striatum; VPall, ventral pallidum; VMH, ventromedial hypothalamus; VTA, ventral tegmental area.

parental care except lactation; however, recent work has suggested that fathers might engage in caregiving behavior in disproportionate amounts or provide subtle but qualitatively different forms of care [Finton and Ophir, 2020; Rogers and Bales, 2020]. As a result, variable parental environments attributable to the total care from single or biparental caregiving, or more nuanced variation attributable to individual variation of one or more parents, create the opportunity for differential developmental factors to shape adolescent [Perkeybile et al., 2013] and adult [Rogers and Bales, 2020] phenotypes. Moreover, certain developmental environments can influence a male's decision to bond. For example, males raised by a single parent (mothers only) show delayed partner preference formation in adulthood when compared to biparentally raised animals [Ahern and Young, 2009; Valera-Marín et al., 2021]. Very recently, we have found that uniparental or biparental rearing environments also appear to shape mating tactics as assessed by space use in adult males, whereby uniparentally raised males demonstrate larger (wanderer-like) home ranges and are more likely to be wanderers than biparentally raised males living in seminatural field conditions [Madrid et al., unpubl. data]. 
These points suggest individual-individual interactions during development and in adulthood can shape the reproductive decision-making process in male prairie voles.

\section{Cellular and Molecular Level Effects}

For many years, the prairie vole has served as a model for investigating the neural mechanisms of social behavior [Johnson and Young, 2015; Carter and Perkeybile, 2018; Madrid et al., 2020; López-Gutiérrez et al., 2021; Tripp et al., 2021]. These studies have provided a foundation upon which an understanding of how the cellular and molecular processes that shape cognition can be built. In this last section on the multi-level effects shaping cognition, we will begin to integrate across molecular and cellular level traits and discuss ways in which they correlate with the expression of differential socio-spatial cognitive abilities. We outline this to identify just some of the ways cellular and sub-cellular variation can lead to individual behavioral variation and differential reproductive success within tactics. Indeed, neural, hormonal, and genetic mechanisms of behavior provide clear examples of the differential mechanistic control of the behavioral variability that contributes to these reproductive decisions.

Brain structures within at least two neural circuits, the social decision-making network (SDMN) and the sociospatial memory circuit [O'Connell and Hofmann, 2011, 2012b; Ophir, 2017] (Fig. 2), have been identified as important for the acquisition, processing, storage, and utilization of information necessary to modulate decisionmaking. Within these circuits, molecular mechanisms produce a range of phenotypes (e.g., variability in receptor densities) that function to shape emergent social phenotypes and spatial cognition. The variation that results from these cognitive and behavioral phenotypes can partly account for the adoption of the three prairie vole mating tactics discussed above.

Bonding rests at the heart of the differences between residents and wanderers, and the decision to bond or remain single is central to the bonding process. Neuromodulators like OT, arginine vasopressin (AVP), and dopamine (DA) shape cognition and social behavior by modulating activity within the social brain [Aragona et al., 2003; Goodson, 2008; Aragona and Wang, 2009; Goodson and Thompson, 2010; Prounis and Ophir, 2020]. Indeed, social cognition and behavior appear to be partly shaped by the organizational role of these signaling pathways [Carter et al., 2008]. Interestingly, these signaling molecules also appear to be conserved in multiple pair bonding species, including California mice [Guoynes,
2021], zebra finches [Goodson et al., 2009; Klatt and Goodson, 2013], titi monkeys [Baxter et al., 2020], and humans [Walum et al., 2012]. Male prairie voles receiving injections of DA receptor 1 agonist [Hostetler et al., 2011] or OTR antagonist [Bales and Carter, 2003] early in development typically fail to form partner preferences in adulthood. Additionally, early postnatal exposure to AVP produces high aggression in adult sexually naïve males comparable to that of pair bonded males [Stribley and Carter, 1999]. In adulthood, a coordinated cascade of DA receptor type 2 and OTR binding within the nucleus accumbens (NAc), a node of the SDMN, is necessary for encoding partner-specific social stimuli as rewarding and promoting the formation of a pair bond in the prairie vole [Aragona et al., 2003; Liu and Wang, 2003; Johnson et al., 2017].

The "pair bonding neural circuit" has been well characterized in the prairie vole (Fig. 2), and this network is thought to coordinate the encoding of a social partner's cues as rewarding and to facilitate the selective preference for (and memory of) a specific individual [for reviews see Young and Wang, 2004; Carter et al., 2008; Donaldson and Young, 2008; Johnson and Young, 2015]. Notably, many subunits of the pair bonding neural circuit are nodes of the mesolimbic reward pathway important for assigning valence to environmental information, including the NAc, ventral pallidum (VPall), and ventral tegmental area [Young and Wang, 2004; Johnson and Young, 2015]. Notably, all of these and the remaining supporting structures of the pair bonding circuit are contained within the larger SDMN shared across vertebrates [O'Connell and Hofmann, 2011], and it is reasonable to think about pair bonding as a form of social decision-making. The function of the NAc is of specific interest because its activity appears to be important for modulating social recognition in rodents [Xing et al., 2021], encoding reward for social stimuli [Berridge and Robinson, 1998], and serving as a relay between reward and socio-spatial cognitive processing [Dölen and Malenka, 2014; Ophir, 2017]. OTR density within the NAc has been shown to differ between prairie vole alternative mating tactics, with successful resident males exhibiting more OTR expression than nonbonded wanderers [Ophir et al., 2012]. Additionally, this mating-induced pair bond formation seen in resident males has been shown to be under the control of NAc OTR [Keebaugh et al., 2015] and is sensitive to epigenetic upregulation of OTR gene promoters within the NAc [Wang et al., 2013; Duclot et al., 2016], a mechanism that facilitates social cognition seen across species [Dölen et al., 2013; Loth et al., 2014; Duclot et al., 2016]. These 
results support the hypothesis that high NAc OTR facilitates reward-based social bonding among residents, that NAc OTR is plastic, and that NAc OTR dynamically adjusts based on environmental influences. Thus, OTR within the NAc provides a mechanism by which social context could modulate the reward valence associated with pairing to shape the decision to engage in resident (true and rover) or wandering behavior.

The pair bonding neural circuit also includes structures implicated in the recall of specific cues and their encoded valence, such as the medial amygdala (MeA) and the lateral septum (LS). In particular, high vasopressin receptor (specifically, V1aR) and low OTR densities within the LS have been associated with greater rates of social investigation of familiar individuals [Ophir et al., 2009], suggesting a relationship with poor social memory and low social recognition. These sub-cellular molecular level traits in the cells of the LS potentially predispose males to be poor at forming social preferences for a single partner and to adopt a nonbonded tactic as result. Additionally, manipulation studies have shown that insults to the cells of the MeA, by way of lesion, disrupt the expression of social recognition in male prairie voles and decrease time spent with both partner and pups [Kirkpatrick et al., 1994]. Administration of V1aR or OTR antagonist into the LS blocks mating-induced pair bonding, whereas males that receive AVP administered to the LS form a pair bond in the absence of mating [Liu et al., 2001]. Furthermore, a longitudinal fMRI study observing the functional interactions at the cellular level within nodes of the pair bonding neural circuit demonstrated that pair bond strength was correlated with long-term changes in functional connectivity between the MeA-VPall [LópezGutiérrez et al., 2019]. These data suggest that beyond their roles in pair bonding, the MeA, NAc, VPall, and LS impact social cognition through the involvement of the NAc and VPall in reward and the LS and MeA in social recognition. Evidence of this functional interconnection supports the hypothesis that the LS may act as an "association maker," assessing, recognizing, and assigning valences of and to conspecifics [Sheehan et al., 2004]. Altogether, it appears that these cellular and molecular mechanisms work in combination to modulate the encoding of salient memories (e.g., social identity) to facilitate selective partner preferences in pair bonding males.

Reproductive decision-making is an inherently spatial task because individuals must have the ability to locate potential mates in space and keep track of the activity of conspecific competitors. Thus, the ability to integrate spatial contextual memory with salient social informa-

Cognitive and Behavioral Variability in

Reproductive Decision-Making tion should impact the behavioral decisions that animals make [Phelps and Ophir, 2009]. Structures within the proposed "socio-spatial neural circuit" (Fig. 2) are important for encoding, recalling, and analyzing information about the context in which individuals are making reproductive decisions [Phelps et al., 2010; Ophir, 2017]. This circuit is composed of the HPC, retrosplenial cortex (RSC), anterior thalamus (and specifically the laterodorsal thalamic nucleus subunit, LDThal), septohippocampal nucleus (SHi), and LS [Ophir, 2017]. Differential neural modulation and activity within this proposed circuit is hypothesized to correspond with variable forms of cognition and behaviors within and between tactics. For example, reproductively successful residents express denser OTR in the HPC and SHi, and denser V1aR in the RSC and LDThal compared to unsuccessful residents [Ophir et al., 2008b, 2012]. The heightened sensitivity to OT and AVP within these brain areas combined with their known roles for modulating learning and memory have led to the suggestion that "good" socio-spatial cognitive abilities might benefit resident males [Phelps and Ophir, 2009; Ophir, 2017]. In support of this, we have recently found that lesioning the CA1 region of the dorsal HPC increases territory size in residents, representing a shift from resident-like space use to wanderer-like space use [Finton et al., unpubl. data]. Thus, HPC function is not only important for spatial learning and navigation [Eichenbaum, 2017], but it might enable animals to engage in tacticspecific forms of space use. Whether this shift in space use is HPC-OTR-dependent remains an open question. However, reproductively successful wanderers, which traverse large territories, express low OTR density in the HPC compared to unsuccessful wanderers [Ophir et al., 2012], suggesting that HPC OTR might contribute to tactic-specific patterns of space use.

Much like OTRs within the HPC, resident males with greater reproductive success also show denser V1aR within the RSC and the LDThal [Ophir et al., 2008b; Okhovat et al., 2015]. Because these structures are important for contextual spatial memory [Vann et al., 2009; Miller et al., 2014], the high LDThal and RSC V1aR density might reflect the natural variation in AVP regulation of integrating social contextual cues with spatial information. Thus, if tracking conspecifics in space and time is important for successful resident behavior, then AVP$\mathrm{V} 1 \mathrm{aR}$ activity within neural structures dedicated to spatial cognition might enable residents to best track conspecifics in space and time and maximize resident-typical behavior. Alternatively, males participating in EPCs (rovers and wanderers) express sparse V1aR in these regions 
[Ophir et al., 2008b; Okhovat et al., 2015]. Therefore, low potential for AVP-V1aR binding might facilitate multifemale mating behavior by restricting a male's ability to integrate socio-spatial information, an idea consistent with the "adaptive forgetting" hypothesis discussed above. Thus, variability among cellular and molecular traits have the potential to account for variability in spatial cognition, which in turn could impact mating tactics and mate fidelity.

The control of RSC function on socio-spatial cognition and mating tactics goes beyond the hormone-receptor dynamic and can be studied at the genetic and epigenetic levels. A single nucleotide polymorphic difference in the V1aR gene (avpra1), specifically contained within the RSC, has been implicated in shaping mating tactics [Okhovat et al., 2015, 2018]. These studies have demonstrated that allelic variation of avprla in the RSC predisposes some individuals to be more sensitive to epigenetic modification during development, leading to differential genetic expression, neuropeptide receptor differences, and variable cognitive and behavioral traits. Specifically, individuals with an allele coding for higher transcription rates of $\mathrm{V} 1 \mathrm{aR}$ protein (i.e., $\mathrm{HI} / \mathrm{HI}$ ) express more V1aR within its RSC neurons compared to individuals with an alternative allelic profile producing lower avprla transcription (i.e., LO/LO) [Okhovat et al., 2015]. At the level of the individual, high RSC V1aR density is correlated with high sexual fidelity, whereas low RSC V1aR is associated with poor socio-spatial memory and more frequent extra-pair encounters with multiple females [Okhovat et al., 2015]. Additionally, the genetic sequences that encode these allelic differences have differential sensitivity to epigenetic modification. LO/LO avprla genotypes contain more $\mathrm{CpG}$ sites than $\mathrm{HI} / \mathrm{HI}$ alleles and they are, therefore, more susceptible to epigenetic methylation during development [Phelps et al., 2017; Okhovat et al., 2018]. In addition to accounting for genotype-phenotype differences in mating tactics, these and other data [e.g., Kelly et al., 2020; Danoff et al., 2021] suggest that experience (developmental or otherwise) could epigenetically modify the pre-existing genetic differences that correlate with behavioral differences and characterize successful mating tactics.

The variability in both genotype and molecular phenotype in the example above underscores the ways in which different sub-cellular levels of biological organization can interact with the external environment (in this case through epigenetic modification), to span multiple levels of biological organization in a way that functionally impacts cognition and behavior at the individual lev- el. Integrating trait expression across these multiple levels of biological organization provides a better understanding of the full suite of mechanisms modulating variability in behavior throughout development and in adulthood.

\section{Concluding Remarks}

Using alternative mating tactics in the socially monogamous prairie vole as an example of variation in behavior, we explored the ways in which population, individual, cellular, and molecular levels shape individual cognitive processes and drive adaptive reproductive decision-making (see Fig. 1). We discussed how some molecular level actions, including genetic and epigenetic regulatory mechanisms coordinating signaling-receptor dynamics, can coordinate cellular level (neural) activity. These interactions can take place throughout development to produce organizational effects with long-term and usually irreversible consequences and can have activational consequences during adulthood with functional implications for shaping cognitive and behavioral variation. We have also argued that traits at the individual and population levels (namely the behavior of social partners and population demographics) can directly impact individual cognitive processes through their roles in constituting the social environment that individuals face, thereby constraining the success of a chosen tactic.

Different patterns of cognitive processing emerge from the interaction of higher and lower levels of organization and can be best studied through their effects on behavior. Behavioral variation allows an individual to effectively adapt to changes in ecological factors and the changing social environment [Johnston and Gottlieb, 1990]. Indeed, behavioral variability is present in just about all domains of life and plays an important role in the evolution of a species. Understanding variable processes and traits across multiple levels of biological organization can help us better understand how behavioral variability arises at the level of the individual. Only through a clear understanding of the proximate mechanisms that enable the expression of behavior can the full scope of the functional significance and the ultimate adaptive value of behavior be achieved. More research on the cognitive mechanisms modulating reproductive decision-making, particularly with a focus on places where biological levels of organization interact, will provide a better understanding of the variable expression and evolution of behavior. 


\section{Acknowledgements}

We wish to thank Walt Wilczynski for all that he did for our field, for being a kind and generous mentor, and for giving A.G.O. his start in a research career.

\section{Statement of Ethics}

Ethics approval was not required.

\section{Conflict of Interest Statement}

The authors have no conflicts of interest to declare.

\section{Funding Sources}

The writing of this manuscript was facilitated by support from the National Science Foundation to S.A.F. (2019285657). The work discussed herein was supported, in part, by the National Science Foundation (1354760) and the National Institutes of Health (Eunice Kennedy Shriver National Institute of Child Health and Human Development HD079573) to A.G.O.

\section{Author Contributions}

Both authors (S.A.F. and A.G.O.) conceived of and wrote this manuscript.

\section{Data Availability Statement}

No data were presented in this review.

\section{References}

Adami C, Ofria C, Collier TC. Evolution of biological complexity. Proc Natl Acad Sci U S A. 2000 Apr 25;97(9):4463-8.

Ahern TH, Young LJ. The impact of early life family structure on adult social attachment, alloparental behavior, and the neuropeptide systems regulating affiliative behaviors in the monogamous prairie vole (Microtus ochrogaster). Front Behav Neurosci. 2009 Aug 27;3: 17.

Angeloni L, Bradbury JW, Charnov EL. Body size and sex allocation in simultaneously hermaphroditic animals. Behav Ecol. 2002 May 1;13(3):419-26.

Aragona BJ, Liu Y, Curtis JT, Stephan FK, Wang $Z$. A critical role for nucleus accumbens dopamine in partner-preference formation in male prairie voles. J Neurosci. 2003 Apr 15;23(8): 3483-90.

Aragona BJ, Wang Z. Dopamine regulation of social choice in a monogamous rodent species. Front Behav Neurosci. 2009 Aug 11;3:15.

Bales KL, Carter CS. Developmental exposure to oxytocin facilitates partner preferences in male prairie voles (Microtus ochrogaster). Behav Neurosci. 2003 Sep 1;117(4):854-9.

Bateson P. The active role of behaviour in evolution. Biol Philos. 2004 Mar 1;19(2):283-98.

Baur J, Nsanzimana JD, Berger D. Sexual selection and the evolution of male and female cognition: a test using experimental evolution in seed beetles. Evolution. 2019 Dec 1;73(12): 2390-400.

Baxter A, Anderson M, Seelke AM, Kinnally EL, Freeman SM, Bales KL. Oxytocin receptor binding in the titi monkey hippocampal formation is associated with parental status and partner affiliation. Sci Rep. 2020 Oct 14;10(1): 17301.
Berridge KC, Robinson TE. What is the role of dopamine in reward: hedonic impact, reward learning, or incentive salience? Brain Res Brain Res Rev. 1998 Dec 1;28(3):309-69.

Blocker TD, Ophir AG. Social recognition in paired but not single male prairie voles. Anim Behav. 2015 Oct 1;108:1-8.

Blocker TD, Ophir AG. A preference to bond? Male prairie voles form pair bonds even in the presence of multiple receptive females. Anim Behav. 2016 Dec 1;122:89-97.

Blondel DV, Wallace GN, Calderone S, Gorinshteyn M, St Mary CMCM, Phelps SM. Effects of population density on corticosterone levels of prairie voles in the field. Gen Comp Endocrinol. 2016 Jan 1;225:13-22.

Bouffet-Halle A, Mériguet J, Carmignac D, Agostini S, Millot A, Perret S, et al. Density-dependent natural selection mediates harvest-induced trait changes. Ecol Lett. 2021 Apr; 24(4):648-57.

Carter CS, Boone EM, Bales KL. Early experience and the developmental programming of oxytocin and vasopressin. In: Bridges RS, editor. Neurobiology of the parental brain. New York: Academic Press; 2008. p. 417-33.

Carter CS, Getz LL, Cohen-Parsons M. Relationships between social organization and behavioral endocrinology in a monogamous mammal. In: Rosenblatt JS, Beer C, Busnel MC, Slater PJB, editors. Advances in the study of behavior. New York: Academic Press; 1986. p. 109-45.

Carter CS, Getz LL, Gavish L, McDermott JL, Arnold P. Male-related pheromones and the activation of female reproduction in the prairie vole (Microtus ochrogaster). Biol Reprod. 1980 Dec 1;23(5):1038-45.
Carter CS, Perkeybile AM. The monogamy paradox: what do love and sex have to do with it? Front Ecol Evol. 2018 Nov 29;6:202.

Carter CS, Witt DM, Thompson EG, Carlstead K. Effects of hormonal, sexual, and social history on mating and pair bonding in prairie voles. Physiol Behav. 1988 Jan 1;44(6):691-7.

Clark MM, Galef BG. Effects of intrauterine position on the behavior and genital morphology of litter-bearing rodents. Dev Neuropsychol. 1998 Jan 1;14(2-3):197-211.

Craver CF, Bechtel W. Top-down causation without top-down causes. Biol Philos. 2007 Jul 30; 22(4):547-63

Curtis JT. Does fertility trump monogamy? Anim Behav. 2010 Aug 1;80(2):319-28.

Danoff JS, Wroblewski KL, Graves AJ, Quinn GC, Perkeybile AM, Kenkel WM, et al. Genetic, epigenetic, and environmental factors controlling oxytocin receptor gene expression. Clin Epigenetics. 2021 Jan 30;13(1):23.

Demas GE, Moffatt CA, Drazen DL, Nelson RJ. Castration does not inhibit aggressive behavior in adult male prairie voles (Microtus ochrogaster). Physiol Behav. 1999 Mar 1; 66(1):59-62.

Dluzen DE, Carter CS. Ovarian hormones regulating sexual and social behaviors in female prairie voles, Microtus ochrogaster. Physiol Behav. 1979 Sep 1;23(3):597-600.

Dölen G, Darvishzadeh A, Huang KW, Malenka RC. Social reward requires coordinated activity of nucleus accumbens oxytocin and serotonin. Nature. 2013 Sep;501(7466):179-84.

Dölen G, Malenka R. The emerging role of nucleus accumbens oxytocin in social cognition. Biol Psychiatry. 2014 Sep 1;76:354-5.

Dominey WJ. Alternative mating tactics and evolutionarily stable strategies. Am Zool. 1984 May;24(2):385-96. 
Donaldson ZR, Young LJ. Oxytocin, vasopressin, and the neurogenetics of sociality. Science. 2008 Nov 7;322(5903):900-4.

Dougherty LR, Guillette LM. Linking personality and cognition: a meta-analysis. Philos Trans R Soc Lond B Biol Sci. 2018 Sep 26;373(1756): 20170282.

Drickamer LC. Intra-uterine position and anogenital distance in house mice: consequences under field conditions. Anim Behav. 1996 Apr 1;51(4):925-34.

Duckworth RA. The role of behavior in evolution: a search for mechanism. Evol Ecol. 2009 Jul; 23(4):513-31.

Duclot F, Wang H, Youssef C, Liu Y, Wang Z, Kabbaj M. Trichostatin A (TSA) facilitates formation of partner preference in male prairie voles (Microtus ochrogaster). Horm Behav. 2016 May 1;81:68-73.

Dukas R. Cognitive ecology: the evolutionary ecology of information processing and decision making. Chicago: University of Chicago Press; 1998.

Eichenbaum $\mathrm{H}$. The role of the hippocampus in navigation is memory. J Neurophysiol. 2017 Apr 1;117(4):1785-96.

Eronen MI, Brooks DS. Levels of organization in biology. In: Zalta EN, editor. Stanford encyclopedia of philosophy archive. 2018. Available from: https://plato.stanford.edu/archives/spr2018/entries/levels-org-biology.

Ferguson B, Fuentes SM, Sawrey DK, Dewsbury DA. Male preferences for unmated versus mated females in two species of voles (Microtus ochrogaster and M. montanus). J Comp Psychol. 1986 Sep;100(3):243-7.

Finton CJ, Ophir AG. Prairie vole offspring only prefer mothers over fathers when mothers are a unique resource, yet fathers are the primary source of variation in parental care. Behav Processes. 2020 Feb 1;171:104022.

Fisher JB. Evolution and bird sociality. In: Huxley J, Hardy AC, Ford EB, editors. Evolution as a process. Allen \& Unwin; 1954. p. 71-83.

Gaulin SJC, FitzGerald RW. Home-range size as a predictor of mating systems in Microtus. J Mammal. 1988 May 20;69(2):311-9.

Getz LL, Hofmann JE, Carter CS. Mating system and population fluctuations of the prairie vole, Microtus ochrogaster. Am Zool. 1987 Aug 1;27(3):909-20.

Getz LL, McGuire B, Pizzuto T, Hofmann JE, Frase $\mathrm{B}$. Social organization of the prairie vole (Microtus ochrogaster). J Mammal. 1993; 74(1):44-58.

Gil MA, Hein AM, Spiegel O, Baskett ML, Sih A. Social information links individual behavior to population and community dynamics. Trends Ecol Evol. 2018 Jul 1;33(7):535-48.

Gobrogge KL, Liu Y, Jia X, Wang Z. Anterior hypothalamic neural activation and neurochemical associations with aggression in pairbonded male prairie voles. J Comp Neurol. 2007;502(6):1109-22.
Goodson JL. Nonapeptides and the evolutionary patterning of sociality. Prog Brain Res. 2008 Jan 1;170:3-15.

Goodson JL, Kabelik D, Kelly AM, Rinaldi J, Klatt JD. Midbrain dopamine neurons reflect affiliation phenotypes in finches and are tightly coupled to courtship. Proc Natl Acad Sci U S A. 2009 May 26;106(21):8737-42.

Goodson JL, Thompson RR. Nonapeptide mechanisms of social cognition, behavior and species-specific social systems. Curr Opin Neurobiol. 2010 Dec 1;20(6):784-94.

Griffin AS, Guillette LM, Healy SD. Cognition and personality: an analysis of an emerging field. Trends Ecol Evol. 2015 Apr 1;30(4):207-14.

Guoynes CD. The role of oxytocin and vasopressin on vocal communication and forming, maintaining, and breaking social bonds in the California mouse (Peromyscus californicus) [Internet]. The University of Wisconsin Madison; 2021. Available from: http://www. proquest.com/docview/2583025414/ abstract/21962A790A624B3APQ/1.

Hampton RR, Sherry DF, Shettleworth SJ, Khurgel M, Ivy G. Hippocampal volume and foodstoring behavior are related in parids. Brain Behav Evol. 1995;45(1):54-61.

Harbert KJ, Pellegrini M, Gordon KM, Donaldson ZR. How prior pair-bonding experience affects future bonding behavior in monogamous prairie voles. Horm Behav. 2020 Nov 1; 126:104847.

Hnatczuk OC, Morrell JI. Interaction of male sensory cues and estradiol in the induction of estrus in the prairie vole. Physiol Behav. 1995 Oct 1;58(4):785-90.

Hostetler CM, Harkey SL, Krzywosinski TB, Aragona BJ, Bales KL. Neonatal exposure to the D1 agonist SKF38393 inhibits pair bonding in the adult prairie vole. Behav Pharmacol. 2011 Oct;22(7):703-10.

Jacobs LF, Gaulin SJ, Sherry DF, Hoffman GE Evolution of spatial cognition: sex-specific patterns of spatial behavior predict hippocampal size. Proc Natl Acad Sci U S A. 1990 Aug 1;87(16):6349-52

Johnson ZV, Walum H, Xiao Y, Riefkohl PC, Young LJ. Oxytocin receptors modulate a social salience neural network in male prairie voles. Horm Behav. 2017 Jan 1;87:16-24.

Johnson ZV, Young LJ. Neurobiological mechanisms of social attachment and pair bonding. Curr Opin Behav Sci. 2015 Jun 1;3:38-44.

Johnston TD, Gottlieb G. Neophenogenesis: a developmental theory of phenotypic evolution. J Theor Biol. 1990 Dec 21;147(4):471-95.

Keebaugh AC, Barrett CE, LaPrairie JL, Jenkins JJ, Young LJ. RNAi knockdown of oxytocin receptor in the nucleus accumbens inhibits social attachment and parental care in monogamous female prairie voles. Soc Neurosci. 2015 Oct;10(5):561-70.

Kelly AM, Ong JY, Witmer RA, Ophir AG. Paternal deprivation impairs social behavior putatively via epigenetic modification to lateral septum vasopressin receptor. Sci Adv. 2020 Jul 2;6(36):eabb9116.
Kelly AM, Saunders AG, Ophir AG. Mechanistic substrates of a life history transition in male prairie voles: developmental plasticity in affiliation and aggression corresponds to nonapeptide neuronal function. Horm Behav. 2018 Mar 1;99:14-24.

Kenkel WM, Perkeybile AM, Yee JR, Carter CS. Rewritable fidelity: how repeated pairings and age influence subsequent pair-bond formation in male prairie voles. Horm Behav. 2019 Jul 1;113:47-54.

Kirkpatrick B, Carter CS, Newman SW, Insel TR Axon-sparing lesions of the medial nucleus of the amygdala decrease affiliative behaviors in the prairie vole (Microtus ochrogaster): behavioral and anatomical specificity. Behav Neurosci. 1994 Jun;108(3):501-13.

Klatt JD, Goodson JL. Oxytocin-like receptors mediate pair bonding in a socially monogamous songbird. Proc Biol Sci. 2013 Jan 7; 280(1750):20122396.

Kokko H, Rankin DJ. Lonely hearts or sex in the city? Density-dependent effects in mating systems. Philos Trans R Soc Lond B Biol Sci. 2006 Feb 28;361(1466):319-34.

Krebs JR, Clayton NS, Healy SD, Cristol DA, Patel $\mathrm{SN}$, Jolliffe AR. The ecology of the avian brain: food-storing memory and the hippocampus. Ibis. 1996 Jan;138(1):34-46.

Lietzenmayer LB, Clark DL, Taylor LA. The role of male coloration and ornamentation in potential alternative mating strategies of the dimorphic jumping spider, Maevia inclemens. Behav Ecol Sociobiol. 2019 May 27;73(6):83.

Liu Y, Curtis JT, Wang Z. Vasopressin in the lateral septum regulates pair bond formation in male prairie voles (Microtus ochrogaster). Behav Neurosci. 2001 Aug;115(4):910-9.

Liu Y, Wang ZX. Nucleus accumbens oxytocin and dopamine interact to regulate pair bond formation in female prairie voles. Neuroscience. 2003 Oct 15;121(3):537-44.

López-Gutiérrez MF, Gracia-Tabuenca Z, Ortiz JJ, Camacho FJ, Young LJ, Paredes RG, et al. Brain functional networks associated with social bonding in monogamous voles. Elife. 2021 Jan 14;10:e55081.

López-Gutiérrez MF, Ortiz JJ, Camacho FJ, Young LJ, Paredes RG, Diaz NF, et al. Social bonding induces changes in brain functional connectivity in male and female monogamous voles: a longitudinal fMRI study. bioRxiv. 2019 Jan 1. Epub ahead of print.

Loth E, Poline JB, Thyreau B, Jia T, Tao C, Lourdusamy A, et al. Oxytocin receptor genotype modulates ventral striatal activity to social cues and response to stressful life events. Biol Psychiatry. 2014 Sep 1;76(5):367-76.

MacMahon JA, Phillips DL, Robinson JV, Schimpf DJ. Levels of biological organization: an organism-centered approach. BioScience. 1978 Nov 1;28(11):700-4. 
Madrid JE, Parker KJ, Ophir AG. Variation, plasticity, and alternative mating tactics: revisiting what we know about the socially monogamous prairie vole. In: Naguib M, Barrett L, Healy SD, Podos J, Simmons LW, Zuk M, editors. Advances in the study of behavior. Academic Press; 2020. p. 203-42.

Maynard-Smith J, Szathmary E. The major transitions in evolution. Oxford: Oxford University Press; 1997.

McEwen B. Roles of vasopressin and oxytocin in memory processing. Elsevier Academic Press; 2004. Vol. 50.

McGuire B, Getz LL. Alternative male reproductive tactics in a natural population of prairie voles Microtus ochrogaster. Acta Theriol. 2010 Sep 1;55(3):261-70.

Mendelson TC, Fitzpatrick CL, Hauber ME, Pence CH, Rodríguez RL, Safran RJ, et al. Cognitive phenotypes and the evolution of animal decisions. Trends Ecol Evol. $2016 \mathrm{Nov}$ 1;31(11):850-9.

Miller AM, Vedder LC, Law LM, Smith DM. Cues, context, and long-term memory: the role of the retrosplenial cortex in spatial cognition. Front Hum Neurosci. 2014 Aug 5;8: 586.

Myers JH, Krebs CJ. Sex ratios in open and enclosed vole populations: demographic implications. Am Natural. 1971 Jul 1;105(944): $325-44$.

Niv Y. The primacy of behavioral research for understanding the brain. Behav Neurosci. 2021 Jun 7;135(5):601-9.

O'Connell LA, Hofmann HA. The vertebrate mesolimbic reward system and social behavior network: a comparative synthesis. J Comp Neurol. 2011 Dec 15;519(18):3599-639.

O'Connell LA, Hofmann HA. Evolution of a vertebrate social decision-making network. Science. 2012a Jun 1;336(6085):1154-7.

O'Connell LA, Hofmann HA. Social status predicts how sex steroid receptors regulate complex behavior across levels of biological organization. Endocrinology. 2012b Mar 1;153(3): 1341-51.

Odling-Smee J, Erwin DH, Palkovacs EP, Feldman MW, Laland KN. Niche construction theory: a practical guide for ecologists. Q Rev Biol. 2013 Mar 1;88(1):4-28.

Okhovat M, Berrio A, Wallace G, Ophir AG, Phelps SM. Sexual fidelity trade-offs promote regulatory variation in the prairie vole brain. Science. 2015 Dec 11;350(6266):1371-4.

Okhovat M, Chen IC, Dehghani Z, Zheng DJ, Ikpatt JE, Momoh H, et al. Genetic variation in the developmental regulation of cortical avprla among prairie voles. Genes Brain Behav. 2018 Jan;17(1):36-48.

Oliveira RF, Taborsky M, Brockmann HJ, editors. Alternative reproductive tactics: an integrative approach. Cambridge: Cambridge University Press; 2008 Mar 13.

Ophir AG. Navigating monogamy: nonapeptide sensitivity in a memory neural circuit may shape social behavior and mating decisions. Front Neurosci. 2017 Jul 11;11:397.
Ophir AG, Delbarco-Trillo J. Anogenital distance predicts female choice and male potency in prairie voles. Physiol Behav. 2007 Oct;92(3): $533-40$.

Ophir AG, Gessel A, Zheng DJ, Phelps SM. Oxytocin receptor density is associated with male mating tactics and social monogamy. Horm Behav. 2012 Mar 1;61(3):445-53.

Ophir AG, Phelps SM, Sorin AB, Wolff JO. Social but not genetic monogamy is associated with greater breeding success in prairie voles. Anim Behav. 2008a Mar 1;75(3):1143-54.

Ophir AG, Wolff JO, Phelps SM. Variation in neural $\mathrm{V} 1 \mathrm{aR}$ predicts sexual fidelity and space use among male prairie voles in semi-natural settings. Proc Natl Acad Sci U S A. 2008b Jan 29;105(4):1249-54

Ophir AG, Zheng DJ, Eans S, Phelps SM. Social investigation in a memory task relates to natural variation in septal expression of oxytocin receptor and vasopressin receptor $1 \mathrm{a}$ in prairie voles (Microtus ochrogaster). Behav Neurosci. 2009 Oct;123(5):979-91.

Perkeybile AM, Griffin LL, Bales KL. Natural variation in early parental care correlates with social behaviors in adolescent prairie voles (Microtus ochrogaster). Front Behav Neurosci. 2013 Mar 18;7:21.

Phelps SM, Campbell P, Zheng DJ, Ophir AG. Beating the boojum: comparative approaches to the neurobiology of social behavior. Neuropharmacology. 2010 Jan 1;58(1):17-28.

Phelps SM, Okhovat M, Berrio A. Individual differences in social behavior and cortical vasopressin receptor: genetics, epigenetics, and evolution. Front Neurosci. 2017 Oct 4;11:537.

Phelps SM, Ophir AG. Monogamous brains and alternative tactics: neuronal V1aR, space use and sexual infidelity among male prairie voles. Cognitive ecology II. Chicago, IL: University of Chicago Press; 2009. p. 156-76.

Pizzuto T, Getz LL. Female prairie voles (Microtus ochrogaster) fail to form a new pair after loss of mate. Behav Processes. 1998 Apr 1;43(1): 79-86.

Prounis GS, Foley L, Rehman A, Ophir AG. Perinatal and juvenile social environments interact to shape cognitive behaviour and neural phenotype in prairie voles. Proc Biol Sci. 2015 Nov 22;282(1819):20152236.

Prounis GS, Ophir AG. One cranium, two brains not yet introduced: distinct but complementary views of the social brain. Neurosci Biobehav Rev. 2020 Jan 1;108:231-45.

Rice MA, Hobbs LE, Wallace KJ, Ophir AG. Cryptic sexual dimorphism in spatial memory and hippocampal oxytocin receptors in prairie voles (Microtus ochrogaster). Horm Behav. 2017 Sep 1;95:94-102.

Rice MA, Restrepo LF, Ophir AG. When to cheat: modeling dynamics of paternity and promiscuity in socially monogamous prairie voles (Microtus ochrogaster). Front Ecol Evol. 2018 Sept 19;6:141.
Rice MA, Sanín G, Ophir AG. Social context alters spatial memory performance in free-living male prairie voles. R Soc Open Sci. 2019 Nov 20;6(11): 190743 .

Rogers FD, Bales KL. Revisiting paternal absence: female alloparental replacement of fathers recovers partner preference formation in female, but not male prairie voles (Microtus ochrogaster). Dev Psychobiol. 2020;62(5): 573-90.

Ross HE, Freeman SM, Spiegel LL, Ren X, Terwilliger EF, Young LJ. Variation in oxytocin receptor density in the nucleus accumbens has differential effects on affiliative behaviors in monogamous and polygamous voles. J Neurosci. 2009 Feb 4;29(5):1312-8.

Roth TC, Pravosudov VV. Hippocampal volumes and neuron numbers increase along a gradient of environmental harshness: a large-scale comparison. Proc Biol Sci. 2009 Feb 7; 276(1656):401-5.

Ryan M, Akre K, Kirkpatrick M. Cognitive mate choice. In: Dukas R, Ratcliffe JM, editors. Cognitive ecology II. Chicago: University of Chicago Press; 2009. p. 137-55.

vom Saal FS, Grant WM, McMullen CW, Laves KS. High fetal estrogen concentrations: correlation with increased adult sexual activity and decreased aggression in male mice. Science. 1983 Jun 17;220(4603):1306-9.

Sabol AC, Lambert CT, Keane B, Solomon NG, Dantzer B. How does individual variation in sociality influence fitness in prairie voles? Anim Behav. 2020 May 1;163:39-49.

Schuppli C, Graber SM, Isler K, van Schaik CP. Life history, cognition and the evolution of complex foraging niches. J Hum Evol. 2016 Mar 1;92:91-100.

Sheehan TP, Chambers RA, Russell DS. Regulation of affect by the lateral septum: implications for neuropsychiatry. Brain Res Brain Res Rev. 2004 Aug;46:71-117.

Sherry DF, Jacobs LF, Gaulin SJ. Spatial memory and adaptive specialization of the hippocampus. Trends Neurosci. 1992 Aug;15(8):298303.

Sherry DF, Vaccarino AL, Buckenham K, Herz RS. The hippocampal complex of food-storing birds. Brain Behav Evol. 1989;34(5):30817.

Shettleworth SJ. Cognition, evolution, and behavior. 2nd ed. Oxford: Oxford University Press; 2010 Dec 30.

Shuster SM, Wade MJ. Mating systems and strategies. Princeton: Princeton University Press; 2019 Dec 31.

Shuster SM, Willen RM, Keane B, Solomon NG. Alternative mating tactics in socially monogamous prairie voles, Microtus ochrogaster. Front Ecol Evol. 2019 Feb 7;7:7.

Solomon NG, Jacquot JJ. Characteristics of resident and wandering prairie voles, Microtus ochrogaster. Can J Zool. 2002 May 1;80(5): 951-5. 
Solomon NG, Keane B. Dispatches from the field: sociality and reproductive success in prairie voles. Anim Behav. 2018 Sep 1;143:193-203.

Spencer SJ, Korosi A, Layé S, Shukitt-Hale B, Barrientos RM. Food for thought: how nutrition impacts cognition and emotion. NPJ Sci Food. 2017 Dec 6;1(1):7.

Streatfeild CA, Mabry KE, Keane B, Crist TO, Solomon NG. Intraspecific variability in the social and genetic mating systems of prairie voles, Microtus ochrogaster. Anim Behav. 2011 Dec 1;82(6):1387-98.

Stribley JM, Carter CS. Developmental exposure to vasopressin increases aggression in adult prairie voles. Proc Natl Acad Sci U S A. 1999 Oct 26;96(22):12601-4.

Thomas JA, Birney EC. Parental care and mating system of the prairie vole, Microtus ochrogaster. Behav Ecol Sociobiol. 1979 Jan 1;5(2): $171-86$.

Thomas SA, Wolff JO. Pair bonding and "the widow effect" in female prairie voles. Behav Processes. 2004 Jul 30;67(1):47-54.

Tripp JA, Berrio A, McGraw LA, Matz MV, Davis $\mathrm{JK}$, Inoue $\mathrm{K}$, et al. Comparative neurotranscriptomics reveal widespread species differences associated with bonding. BMC Genomics. 2021 May 31;22(1):399.
Valera-Marín G, Young LJ, Camacho F, Paredes RG, Rodríguez VM, Díaz NF, et al. Raised without a father: monoparental care effects over development, sexual behavior, sexual reward, and pair bonding in prairie voles. Behav Brain Res. 2021 Jun 25;408:113264.

Vann SD, Aggleton JP, Maguire EA. What does the retrosplenial cortex do? Nat Rev Neurosci. 2009 Nov; 10(11):792-802.

Walum H, Lichtenstein P, Neiderhiser JM, Reiss D, Ganiban JM, Spotts EL, et al. Variation in the oxytocin receptor gene is associated with pair-bonding and social behavior. Biol Psychiatry. 2012 Mar 1;71(5):419-26.

Wang H, Duclot F, Liu Y, Wang Z, Kabbaj M. Histone deacetylase inhibitors facilitate partner preference formation in female prairie voles. Nat Neurosci. 2013 Jul;16(7):919-24.

Wekesa KS, Lepri JJ. Removal of the vomeronasal organ reduces reproductive performance and aggression in male prairie voles. Chem Senses. 1994 Jan 1;19(1):35-45.

Williams JR, Catania KC, Carter CS. Development of partner preferences in female prairie voles (Microtus ochrogaster): the role of social and sexual experience. Horm Behav. $1992 \mathrm{Sep}$ 1;26(3):339-49.
Winslow JT, Hastings N, Carter CS, Harbaugh $\mathrm{CR}$, Insel TR. A role for central vasopressin in pair bonding in monogamous prairie voles. Nature. 1993 Oct;365(6446):545-8.

Wolff JO, Dunlap AS. Multi-male mating, probability of conception, and litter size in the prairie vole (Microtus ochrogaster). Behav Processes. 2002 May 28;58(1):105-10.

Wysocki CJ, Kruczek M, Wysocki LM, Lepri JJ. Activation of reproduction in nulliparous and primiparous voles is blocked by vomeronasal organ removal. Biol Reprod. 1991 Oct 1;45(4): 611-6.

Xing B, Mack NR, Guo KM, Zhang YX, Ramirez B, Yang SS, et al. A subpopulation of prefrontal cortical neurons Is required for social memory. Biol Psychiatry. 2021 Mar 1;89(5): $521-31$

Young LJ, Wang Z. The neurobiology of pair bonding. Nat Neurosci. 2004 Oct 1;7(10): 1048-54.

Zheng DJ, Foley L, Rehman A, Ophir AG. Social recognition is context dependent in single male prairie voles. Anim Behav. 2013a Nov 1; 86(5):1085-95.

Zheng DJ, Larsson B, Phelps SM, Ophir AG. Female alternative mating tactics, reproductive success and nonapeptide receptor expression in the social decision-making network. Behav Brain Res. 2013b Jun 1;246:139-47. 